\title{
Review
}

Medical Principles
and Practice

Received: September 23, 2007

DOI: $10.1159 / 000129603$

Revised: February 21, 2008

\section{The Neurology of Psychosis}

\author{
Femi Oyebode \\ Department of Psychiatry, University of Birmingham, Queen Elizabeth Psychiatric Hospital, Birmingham, UK
}

\author{
Key Words \\ Psychosis · Epilepsy · Schizophrenia · Delusional \\ misidentification syndromes
}

\begin{abstract}
The neural basis of psychosis is yet to be fully elucidated. In this review the contribution of schizophrenia-like psychosis of epilepsy, delusional misidentification syndromes and psychotic phenomena, such as auditory and visual hallucinations, to our understanding of the neural basis of psychosis is examined. Schizophrenia-like psychosis of epilepsy is associated with seizures originating from the limbic structures. Reduced seizure frequency, left-sided electrical foci, and neurodevelopmental lesions manifesting as cortical dysgenesis are known to influence the likelihood of developing schizophrenia-like psychosis of epilepsy. The delusional misidentification syndromes are a group of rare psychiatric symptoms in which impairments of face recognition memory are present. These conditions appear also to be associated with organic lesions affecting limbic structures and also involving both the frontal and parietal lobes. There is evidence that right-sided lesions predominate in the aetiology of delusional misidentification syndromes. Thus, the common link between schizophrenia, schizophrenia-like psychosis of epilepsy and delusional misidentification syndromes appears to be involvement of limbic structures in their pathophysiology. Discrete psychotic phenomena such as visual and auditory hallucinations appear to arise from functional
\end{abstract}

changes in the same cortical areas subserving the normal physiological functions of vision and audition but also involving limbic structures. In conclusion, the limbic structures appear to be central to the psychopathology of psychosis but with involvement of frontal and parietal structures. These inquiries are revealing as much about psychosis as they are about the nature of normal brain function.

Copyright $\odot 2008$ S. Karger AG, Basel

\section{Introduction}

Schizophrenia is the paradigmatic psychosis. It is assumed that it has a neurological basis, even if as yet not fully explicated. In the extensive review of the world literature conducted by Davison $[1,2]$, it was demonstrated that particular medical conditions, particularly neurological conditions, were associated with schizophrenia. Epilepsy, acquired brain injury, encephalitis lethargica, Parkinson's disease, Wilson's disease, Huntington's disease, narcolepsy, subarachnoid haemorrhage, a number of metabolic and toxic disturbances, and others were readily identified. The unifying feature appeared to be involvement of limbic structures such as the temporal lobes and the diencephalon. The aim of this review is to examine the current evidence for the neural basis of psychosis, using schizophrenia as a prime example. The relationship between schizophrenia and cerebral pathology will be discussed, as will the relationship between dis-

\section{KARGER}

Fax +4161306 1234

E-Mail karger@karger.ch

www.karger.com (c) 2008 S. Karger AG, Basel

1011-7571/08/0174-0263\$24.50/0

Accessible online at:

www.karger.com/mpp
Femi Oyebode

Department of Psychiatry, University of Birmingham

Queen Elizabeth Psychiatric Hospital, Mindelsohn Way, Edgbaston

Birmingham B15 2QZ (UK)

Tel. +44 121678 2526, E-Mail femi.oyebode@bsmht.nhs.uk 
crete psychotic syndromes such as delusional misidentification syndromes and cerebral pathology. The importance of specific sites for the development of psychotic symptoms will be discussed. Modern functional imaging techniques have made it possible to identify the relevance of the functioning of particular neural systems to the experience of psychotic phenomena. Alongside the development of new investigational tools and techniques, it is also the case that researchers have moved from simply studying psychiatric disorders such as schizophrenia to examining rare and discrete syndromes such as delusional misidentification syndromes. Further, interest in investigating symptoms such as hallucinations or delusions on their own particularly with respect to their underlying pathophysiology has grown in the past decade or so. These issues will all be explored as it is clear that any understanding of the complex neural basis of the psychoses in general or of the component abnormalities will assist our understanding of brain function in general and of the primary mechanisms underlying many of the neural processes and modules involved in perception, volition, thinking, and language.

\section{Epilepsy and Psychosis}

There is an undeniable increase in the prevalence of psychiatric disorders in patients with epilepsy [3]. There is evidence that 'focal' epilepsy deriving from limbic structures is more likely to be associated with psychiatric complications than 'generalised' epilepsy [4].

The most important findings have been the demonstration of an affinity between epilepsy and psychosis [57]. Much interest has focused on this relationship with a view to determining which seizure factors predict psychosis. The classical studies are those by Slater et al. [811]. They concluded that there is a greater than chance association between temporal lobe epilepsy and schizophrenia-like psychosis.

The importance of this association is clearly that schizophrenia-like psychosis of epilepsy can serve as a model for functional schizophrenia [12]. If we are able to identify the factors that determine the likelihood of schizophrenia-like psychosis of epilepsy, we may be able to come to a closer understanding of the origins of schizophrenia. Thus, in the period 1960 to date, there has been considerable interest in the overlap between epilepsy and schizophrenia. Factors such as prevalence of psychosis in patients with epilepsy [4, 13-15], age of onset of epilepsy in those patients who developed schizophrenia-like psy- chosis [13, 16-19], duration of epilepsy before the development of schizophrenia-like psychosis [16, 20], and clinical features of schizophrenia-like psychosis of epilepsy $[2,21-26]$ have been investigated.

It is now generally accepted that temporal lobe epilepsy has a special relationship with schizophrenia-like psychosis [27], although this proposition has once again come under attack [28]. There is evidence that there is an inverse relationship between seizure frequency and the onset of schizophrenia-like psychosis [8, 16, 29-31]. There is also evidence that the laterality of the electrical focus is important. Left-sided focus has been shown to be associated with schizophrenia-like psychosis and right-sided focus with mood disturbance $[15,20,32]$. Some authors have argued that these findings can equally be interpreted as showing that an excess of bilateral foci are associated with schizophrenia-like psychosis [33] and furthermore, there is only limited evidence that lateralized structural damage to the cerebral hemisphere plays a major role in determining the phenomenology of psychotic illness [22]. It is also significant that the original distinctions between preictal, postictal and interictal psychoses has come under scrutiny and there is some evidence that postictal psychosis develops over time into interictal psychosis [34].

The neuropathology of the lesions associated with temporal lobe epilepsy has attracted interest. Hamartomas are more often associated with schizophrenia-like psychosis of epilepsy than any other changes [27], but this has not been confirmed by others $[15,35]$. An association of cortical dysgenesis with development of schizophrenia-like psychosis has also been reported [36, 37]. There is evidence of larger cerebral ventricles, excess periventricular gliosis, and more focal damage in patients with epilepsy who develop psychosis [38]. There are also reports of damage to the hippocampus, amygdala and thalamus and of specific dendritic abnormalities [36]. More recently, high density calbindin-reactive neurons in the CA4 region have been reported amongst other more general pathological changes in the hippocampus [39]. Further functional abnormalities have been demonstrated on in vivo magnetic resonance spectroscopy, including marked volumetric reductions in the hippocampus and amygdala with particular prominence on the left [40], and focal hyperfusion in the left temporal lobe and amygdala has been shown on SPECT [41]. Interestingly, temporal lobectomy for intractable epilepsy can be followed by schizophrenia-like psychosis [14, 42-44]. This observation is yet to be fully explained. 
These studies of the association between epilepsy and schizophrenia-like psychosis implicate the limbic structures as the likely neural site for schizophrenic psychosis and perhaps more importantly identify the left hemisphere as being of particular importance. Furthermore, the finding of neurodevelopmental anomalies such as cortical dysgenesis in association with psychosis and the reported specific dendritic abnormalities all hint at the possibility that developmental anomalies and changes in neural connections may underlie psychosis.

Supporting evidence is also available from findings of ictal phenomena in schizophrenia, although these are less robust. There are reports of clinical phenomena that are more typical of epilepsy occurring in schizophrenia, and there is substantial evidence of abnormal electroencephalograph recordings in schizophrenia, but the consensus is that these abnormalities are not typical of epilepsy. Nonetheless, interest in the interrelationships between epilepsy and schizophrenia continues unabated and both empirical and theoretical works on this subject continue [24, 45-49], including the role of kindling [33, 50-52].

In summary, the type of epilepsy, site and neuropathology of the underlying lesion, laterality of the electrical focus and seizure frequency have been shown to contribute to the likelihood of developing psychosis in the context of epilepsy. Thus, complex or partial seizures originating in the temporal lobes, particularly the left temporal lobe, and associated with neurodevelopmental anomalies are implicated. The common substratum between psychosis associated with epilepsy and functional schizophrenia is the limbic system. The question is how far these identified factors assist in deepening our understanding of the neurological basis of psychosis. In the next section, the delusional misidentification syndromes, which are a group of discrete psychotic phenomena, will be examined for their contribution to our understanding of psychosis.

\section{Delusional Misidentification Syndromes}

Delusional misidentification syndromes (DMS) include a number of discrete but related syndromes which have in common the concept of the double [53]. These syndromes include Capgras syndrome, Fregoli syndrome, syndrome of intermetamorphosis, syndrome of subjective doubles [54] and syndrome of inanimate doubles [55]. These syndromes are important insofar as they have been shown to have a significant organic contribution
$[53,56]$. Neuropsychiatric conditions associated with Capgras syndrome, for example, include Alzheimer's dementia [57-60], Lewy body disease [61-64], multi-infarct dementia [61, 65-67], traumatic brain injury [68-71], epilepsy [72], cerebrovascular disease [73], pituitary tumour $[74,75]$, multiple myeloma [76], multiple sclerosis [77, 78], viral encephalitis [79], and frontal lobe pathology [80]. It is estimated that between 25 and $40 \%$ of DMS cases occur in the context of an organic aetiology [56].

The interest in studying the above conditions comes, in part, from the similarity with prosopagnosia. Prosopagnosia is the inability to recognise familiar faces and has been shown to result from unilateral right hemisphere damage, although it is likely that bilateral damage is necessary for prosopagnosia to occur. DMS, where they involve misidentification of persons, appear also to involve impairment of face processing, the distinguishing characteristic of prosopagnosia. Thus, the opportunity exists for the first time to study the neurological substrate as well as the neuropsychological processes underpinning discrete psychotic symptoms.

Unilateral right hemisphere lesions are more frequently associated with DMS than left hemisphere lesions [81$84]$ and this has been demonstrated as right hemisphere hypoperfusion on SPECT $[85,86]$, although the majority of cases involve bilateral lesions [87]. Lesions in the frontal cortex [88] and in the temporal cortex $[81,89,90]$ have also been reported. In dementia, CT scan studies have shown DMS to be associated with global atrophy [91-93], usually in combination with focal right hemisphere lesions [82] including right hemisphere hypoperfusion of the parietal and occipital lobes on SPECT [64].

There is evidence of impairment of face recognition in DMS $[94,95]$. However, these abnormalities are also present, albeit to a lesser degree, in patients with psychosis without DMS [96, 97]. These impairments have led Ellis and Young to suggest that Capgras syndrome is a mirror image of prosopagnosia $[98,99]$. In prosopagnosia, the principal route to overt face recognition, the ventral pathway from the visual cortex to the temporal lobes via the inferior longitudinal fasciculus, is disrupted. However, a secondary dorsal pathway, from the visual cortex via the inferior parietal lobule, believed to be involved in registering the emotional significance of a face is intact [100]. In Capgras syndrome, it is postulated that the ventral route remains intact whereas the dorsal pathway is disrupted in some way. Limited empirical support for this model has been reported $[95,101]$. This approach to understanding DMS is novel and original but it is important to emphasise that there is some evidence that individuals 
with no history of psychiatric illness or current psychiatric illness can also describe experiences that are similar to DMS, albeit in a transient fashion [102]. Furthermore, hyperfamiliarity with unknown faces has been described following right temporo-occipital damage [103], but in this case, there was no evidence of associated delusional belief, only of misrecognition of unknown faces as familiar. This condition is distinct from prosopagnosia and in the reported case occurred in the presence of preservation of recognition of familiar faces.

There are other neuropsychological models for understanding DMS [53, 97]. These include the proposals (a) that DMS develop from feelings of derealisation and depersonalisation [104], (b) that memory disconnection between stored representations and new information is at the root of DMS [105], (c) that the failure to adequately update episodic memory which results in discrepancies between percept and stored image can explain DMS [94], and (d) that disruption of the processes that identify uniqueness to objects and events is at the core of DMS [106].

The contribution of the investigation of DMS to our understanding of the neurology of psychosis is that using the model of a discrete symptom has helped to provide a testable hypothesis regarding how psychotic symptoms may arise and which particular neural sites may be involved. Once again, what is apparent is that limbic structures and their manifold interactions with the frontal cortex are involved. It is surprising that the face processing deficits demonstrated in DMS are present whether or not the patient continues to express delusional beliefs. In other words, these neuropsychological deficits are stable over time, and how they relate to the psychotic state is yet to be fathomed. As in epilepsy, the involvement of limbic structures and the influence of laterality effects stand out.

\section{Neural Basis of Auditory and Visual Hallucinations}

In the section above, psychiatric syndromes with discrete but related phenomena are discussed with respect to the underpinning neural substrate. In the past decade there has been increasing interest in investigating individual symptoms which occur as part of psychiatric disorders such as schizophrenia, bipolar mood disorder or rare conditions such as Charles Bonnet syndrome. The aim has been to get a deeper understanding both of these phenomena and their relationships to the normal brain mechanisms that deal with functions such as vision and audition. The development and use of functional imaging studies, particularly fMRI, has revolutionised this subject. What is important to emphasise is that this approach does not rely on the study of rare phenomena such as DMS, but on ubiquitous psychopathology such as auditory hallucinations.

It has been shown that auditory hallucinations in schizophrenia are associated with reduced activity in the left middle temporal gyrus during listening tasks [107], and there is widespread involvement of frontal gyrus/insula and middle temporal gyri bilaterally and on the right hemisphere, additional involvement of the superior temporal gyrus, middle frontal gyrus, posterior parietal cortex, thalamus, inferior colliculus, anterior cingulated gyrus, and also of left hippocampus and parahippocampus gyrus [108]. Other abnormalities have also been reported $[107,109,110]$. What is most striking is that the observed functional impairments are in the same areas that normally deal with expressive and receptive speech [111, 112]. These functional abnormalities are probably based on demonstrable structural changes in the left transverse temporal gyrus, left inferior supramarginal gyrus and middle/inferior right prefrontal gyri [113]. These findings pointing towards both the structural and functional abnormalities associated with auditory hallucinations occur against the background of an increasing understanding of the neuroanatomy of language expression and comprehension in all its complexity $[109,112,114]$. For example, there is now evidence that the perception of voices in the external auditory space is subserved by auditory cortex posterior to Heschl's gyrus, which is located in the planum temporale and the inferior parietal lobule. There is a suggestion that the left planum temporale is more involved in this function, which suggests that actual spatial location of the voice is less important for the purpose of locating a heard voice in external space than in internal space [114]. It has been argued that several domains have been implicated in the pathophysiology of auditory hallucinations including hearing and language, sense of reality, attention, emotional response, memory functions, self-monitoring and impulse control [115]. This simply emphasises the complexity of the task of unravelling the myriad contributions of various systems to the experience of auditory hallucinations.

In much the same way that auditory hallucinations in schizophrenia have been studied, the functional impairments associated with visual hallucinations have also been investigated. It has been shown that in Charles Bonnet syndrome, a rare condition in which reduced acuity is associated with vivid visual hallucinations, three distinct visual experiences are demonstrable. These include 
extended landscape scenes, grotesque disembodied and distorted faces with prominent teeth and eyes, and visual persistence and delayed palinopsia [116]. In addition to the increasing knowledge of the phenomenology of visual hallucinations as described above, there is a gradual increase in understanding of the brain mechanisms of conscious visual experience [117]. The role of the right occipito-temporal junction has been shown [118] and the importance of extra-striate areas as well as the primary visual cortex in phenomenal vision, that is, the seeing of colours, brightness, depths, shades, and whether in true perception, dreams, hallucinations, phosphenes or imagery is starting to attract interest [119]. What is becoming apparent as with auditory hallucinations is that the areas that normally deal with conscious visual perception are also implicated in visual hallucinations [120]. This is further confirmed in cases where structural brain damage precedes the development of visual hallucinations as in subjects recovering from cortical blindness who experience visual hallucinations. The evidence is that the visual hallucination is accompanied by hyperexcitability bilaterally in the parieto-occipital cortex [121].

\section{Conclusion}

The neurology of psychosis is gradually being understood. This involves recognising the neural sites, cellular basis and pathology of psychotic experiences. It is now quite clear that the functioning of the varying limbic structures is intimately related to psychosis. This is demonstrated by findings in psychosis associated with epilepsy, neurological findings in DMS, and the emerging pathophysiology of visual and auditory hallucinations. It is also quite manifest that there are laterality effects as well as influences deriving both from the frontal and parietal structures. This suggests that limbic abnormalities on their own are not responsible for psychosis or for the component psychopathologies in psychosis. There is little doubt that in the absence of typical or pathognomonic structural cerebral lesions, functional impairments demonstrable on functional imaging coupled with neuropsychological deficits are likely to be the investigative tools for clinical diagnosis in the future.

\section{References}

$>1$ Davison K: Schizophrenia-like psychoses as- $>10$ Slater E, Moran PA: The schizophrenia-like sociated with organic cerebral disorders: A psychoses of epilepsy: Relation between ages review. Psychiatr Dev 1983;1:1-33.

$>2$ Cutting J: Physical illness and psychosis. Br $>11$ J Psychiatry 1980;136:109-119.

$>3$ Standage KF: Psychiatric symptom patterns in epileptics in a mental hospital. Guys Hosp Rep 1972;121:299-305.

-4 Shukla GD, Srivastava ON, Katiyar BC, Joshi V, Mohan PK: Psychiatric manifestations in temporal lobe epilepsy: A controlled study. Br J Psychiatry 1979;135:411-417.

5 Sigal M: Psychiatric aspects of temporal lobe epilepsy. J Nerv Ment Dis 1976;163:348351.

6 Levine DN, Finklestein S: Delayed psychosis after right temporoparietal stroke or trauma: Relation to epilepsy. Neurology 1982;32: 267-273.

7 Tucker GJ, Price TR, Johnson VB, McAllister T: Phenomenology of temporal lobe dysfunction: A link to atypical psychosis - a series of cases. J Nerv Ment Dis 1986;174:348356.

$>8$ Slater E, Beard AW, Glithero E: The schizophrenialike psychoses of epilepsy. Br J Psychiatry 1963;109:95-150.

$\checkmark 9$ Slater E, Beard AW, Glithero E: Schizophrenia-like psychoses of epilepsy. Int J Psychiatry 1965;1:6-30. psychoses of epilepsy: Relation between ages
of onset. Br J Psychiatry 1969;115:599-600.

Slater E, Beard AW: The schizophrenia-like psychoses of epilepsy, V: Discussion and conclusions. 1963. J Neuropsychiatr Clin Neurosci 1995; 7:372-378; discussion 371372.

12 Trimble MR: The schizophrenia-like psychosis of epilepsy. Neuropsychiatry Neuropsychol Behav Neurol 1992;5:103-107.

13 Taylor DC: Factors influencing the occurrence of schizophrenia-like psychosis in patients with temporal lobe epilepsy. Psychol Med 1975;5:249-254.

14 Jensen I, Larsen JK: Mental aspects of temporal lobe epilepsy. Follow-up of 74 patients after resection of a temporal lobe. Neurol Neurosurg Psychiatry 1979;42:256-265.

15 Sherwin I, Peron-Magnan P, Bancaud J, Bonis A, Talairach J: Prevalence of psychosis in epilepsy as a function of the laterality of the epileptogenic lesion. Arch Neurol 1982;39: 621-625.

16 Flor-Henry P: Psychosis and temporal lobe epilepsy. A controlled investigation. Epilepsia 1969;10:363-395.

17 Taylor DC: Mental state and temporal lobe epilepsy. A correlative account of $100 \mathrm{pa}$ tients treated surgically. Epilepsia 1972;13: 727-765.
18 Taylor DC: Epilepsy and the sinister side of schizophrenia. Dev Med Child Neurol 1977; 19:403-407.

19 Adachi N, Matsuura M, Okubo Y, Oana Y, Takei N, Kato M, Hara T, Onuma T: Predictive variables of interictal psychosis in epilepsy. Neurology 2000;55:1310-1314.

-20 Perez MM, Trimble MR, Murray NM, Reider I: Epileptic psychosis: An evaluation of PSE profiles. Br J Psychiatry 1985;146:155-163.

21 Perez MM, Trimble MR: Epileptic psychosis - diagnostic comparison with process schizophrenia. Br J Psychiatry 1980;137: 245-249.

22 Toone BK, Garralda ME, Ron MA: The psychoses of epilepsy and the functional psychoses: A clinical and phenomenological comparison. Br J Psychiatry 1982;141:256261.

23 Oyebode F, Davison K: Epileptic schizophrenia: Clinical features and outcome. Acta Psychiatr Scand 1989;79:327-331.

24 Tadokoro Y, Oshima T, Kanemoto K: Interictal psychoses in comparison with schizophrenia - a prospective study. Epilepsia 2007;48:2345-2351.

-25 Parnas J, Korsgaard S, Krautwald O, Jensen PS: Chronic psychosis in epilepsy. A clinical investigation of 29 patients. Acta Psychiatr Scand 1982;66:282-293. 
26 Parnas J, Korsgaard S: Epilepsy and psychosis. Acta Psychiatr Scand 1982;66:89-99.

27 Oyebode F: Schizophrenia-like psychosis of epilepsy: A review. Neurol Psychiatry Brain Res 1993;2:21-25.

-28 Adachi N, Onuma T, Hara T, Matsuura M, Okubo Y, Kato M, Oana Y: Frequency and age-related variables in interictal psychoses in localization-related epilepsies. Epilepsy Res 2002;48:25-31.

29 Landoldt H: Electroencephalography in epileptic psychoses and schizophrenic episodes (in French). Rev Neurol (Paris) 1956;95:597599.

-30 Seethalakshmi R, Krishnamoorthy ES: The complex relationship between seizures and behavior: An illustrative case report. Epilepsy Behav 2007;10:203-205.

- 31 Domzal TM: Forced normalization (in Polish). Neurol Neurochir Pol 2000;34:719724.

32 Sherwin I: Psychosis associated with epilepsy: Significance of the laterality of the epileptogenic lesion. J Neurol Neurosurg Psychiatry 1981;44:83-85.

- 33 McKenna PJ, Kane JM, Parrish K: Psychotic syndromes in epilepsy. Am J Psychiatry 1985; 142:895-904.

- 34 Tarulli A, Devinsky O, Alper K: Progression of postictal to interictal psychosis. Epilepsia 2001;42:1468-1471.

-35 Jensen I, Larsen JK: Psychoses in drug-resistant temporal lobe epilepsy. J Neurol Neurosurg Psychiatry 1979;42:948-954.

- 36 Scheibel AB: Are complex partial seizures a sequela of temporal lobe dysgenesis? Adv Neurol 1991;55:59-77.

-37 Sachdev P: Schizophrenia-like psychosis and epilepsy: The status of the association. Am J Psychiatry 1998;155:325-336.

- 38 Bruton CJ, Stevens JR, Frith CD: Epilepsy, psychosis, and schizophrenia: Clinical and neuropathologic correlations. Neurology 1994;44:34-42.

- 39 Suckling J, Roberts H, Walker M, Highley JR, Fenwick P, Oxbury J, Esiri MM: Temporal lobe epilepsy with and without psychosis: Exploration of hippocampal pathology including that in subpopulations of neurons defined by their content of immunoreactive calcium-binding proteins. Acta Neuropathol 2000;99:547-554.

-40 Maier M, Mellers J, Toone B, Trimble M, Ron MA: Schizophrenia, temporal lobe epilepsy and psychosis: An in vivo magnetic resonance spectroscopy and imaging study of the hippocampus/amygdala complex. Psych Med 2000;30:571-581.

-41 Jibiki I, Maeda T, Kubota T, Yamaguchi N: 123I-IMP SPECT brain imaging in epileptic psychosis: A study of two cases of temporal lobe epilepsy with schizophrenia-like syndrome. Neuropsychobiology 1993;28:207211.
42 Shaw P, Mellers J, Henderson M, Polkey C, David AS, Toone BK: Schizophrenia-like psychosis arising de novo following a temporal lobectomy: Timing and risk factors. J Neurol Neurosurg Psychiatry 2004;75:10031008.

43 Leinonen E, Tuunainen A, Lepola U: Postoperative psychoses in epileptic patients after temporal lobectomy. Acta Neurol Scand 1994;90:394-399.

44 Stevens JR: Psychiatric consequences of temporal lobectomy for intractable seizures: A 20-30-year follow-up of 14 cases. Psychol Med 1990;20:529-545.

45 Sharp FR, Hendren RL: Psychosis: Atypical limbic epilepsy versus limbic hyperexcitability with onset at puberty? Epilepsy Behav 2007; 10:515-520.

46 Fisekovic S, Burnazovic L: Epileptic psychoses - evaluation of clinical aspects. Bosn J Basic Med Sci 2007;7:140-143.

47 Urrutia AR, Pérez LP, Altable CR: Associations between epilepsy and psychosis: From clinical findings to neurobiology. Psiquiatr Biol 2006; 13:211-219.

48 Koch SS: Neuropsychiatric aspects of psychoses in epilepsy. Nervenheilkunde 2006; 25:331-337.

49 Taylor DC: Schizophrenias and epilepsies: Why? When? How? Epilepsy Behav 2003;4: 474-482.

50 Howland JG, Hannesson DK, Barnes SJ, Phillips AG: Kindling of basolateral amygdala but not ventral hippocampus or perirhinal cortex disrupts sensorimotor gating in rats. Behav Brain Res 2007;177:30-36.

51 Smith PF, Darlington CL: The development of psychosis in epilepsy: A re-examination of the kindling hypothesis. Behav Brain Res 1996;75:59-66.

52 Barcia D: Epileptic schizophrenia-like psychoses and the kindling phenomenon. Eur J Psychiatry 1992;6:5-14.

53 Moselhy H, Oyebode F: Delusional misidentification syndromes: A review of the anglophone literature. Neurol Psychiatr Brain Res 1997:5:21-26.

54 Christodoulou GN: Syndrome of subjective doubles. Am J Psychiatry 1978;135:249-251.

55 Nejad AG, Toofani K: A variant of Capgras syndrome with delusional conviction of inanimate doubles in a patient with grandmal epilepsy. Acta Neuropsychiatr 2006;18:5254.

56 Edelstyn NM, Oyebode F: A review of the phenomenology and cognitive neuropsychological origins of the Capgras syndrome. Int J Geriatr Psychiatry 1999;14:48-59.

57 Förstl H, Almeida OP, Iacoponi E: Capgras delusion in the elderly: The evidence for a possible organic origin. Int J Geriatr Psychiatry 1991;6:845-852.

58 Förstl H, Almeida OP, Owen AM, Burns A, et al: Psychiatric, neurological and medical aspects of misidentification syndromes: A review of 260 cases. Psychol Med 1991;21: 905-910.
59 Förstl H, Besthorn C, Burns A, Geiger KC, et al: Delusional misidentification in Alzheimer's disease: A summary of clinical and biological aspects. Psychopathology 1994;27: 194-199.

60 Diesfeldt HFA, Troost D: Delusional misidentification and subsequent dementia: A clinical and neuropathological study. Dementia 1995;6:94-98.

61 Cummings JL, Barritt CF, Horan M: Delusions induced by procaine penicillin: Case report and review of the syndrome. Int J Psychiatr Med 1987;16:163-168.

62 Edelstyn NMJ, Oyebode F, Booker E, Humphreys GW: Facial processing and the delusional misidentification syndromes. Cognit Neuropsychiatry 1998;3:299-314.

63 Baldwin RC, Snowden JS, Mann DMA: Delusional misidentification in association with cortical Lewy body disease - a case report and overview of possible mechanisms. Int J Geriatr Psychiatry 1995;10:893-898.

64 Ohara K, Morita Y: Case with probable dementia with Lewy bodies, who shows reduplicative paramnesia and Capgras syndrome (in Japanese). Seishin Shinkeigaku Zasshi 2006;108:705-714.

65 Young AW, Reid I, Wright S, Hellawell DJ Face-processing impairments and the Capgras delusion. Br J Psychiatry 1993;162:695698.

66 Oyebode F, Sargeant R: Delusional misidentification syndromes: A descriptive study. Psychopathology 1996;29:209-214.

67 Oyebode F, Edelstyn NMJ, Patel A, Riddoch MJ, Humphreys GW: Capgras syndrome in vascular dementia: Recognition memory and visual processing. Int J Geriatr Psychiatry 1996;11:71-73.

68 Benson DF, Gardner H, Meadows JC: Reduplicative paramnesia. Neurology 1976;26: 147-151.

69 Cutting J: Delusional misidentification and the role of the right hemisphere in the appreciation of identity. Br J Psychiatry 1991;159. 70-75.

-70 Silva JA, Leong GB, Wine DB: Misidentification delusions, facial misrecognition, and right brain injury. Can J Psychiatry 1993;38: 239-241.

71 O'Connor M, Walbridge M, Sandson T, Alexander M: A neuropsychological analysis of Capgras syndrome. Neuropsychiatry Neuropsychol Behav Neurol 1996;9:265-271.

72 Förstl H, Almeida OP, Owen AM, Burns A, Howard R: Psychiatric, neurological and medical aspects of misidentification syndromes: A review of 260 cases. Psychol Med 1991;21:905-910.

73 Frazer SJ, Roberts JM: Three cases of Capgras syndrome. Br J Psychiatry 1994;164: 557-559.

74 Sumners D: Believing your husband has been replaced by an impostor because you have a pituitary tumour. Br Med J (Clin Res Ed) 1984;289:699-700. 
75 Anderson DN: The delusion of inanimate doubles. Implications for understanding the Capgras phenomenon. Br J Psychiatry 1988; 153:694-699.

-76 Edelstyn NJM, Oyebode F: Capgras syndrome in the context of multiple myeloma. Int J Geriatr Psychiatry 1998;13:645-646.

-77 Lebert F, Pasquier F, Steinling M, Cabaret M, Caparros LD, Petit H: SPECT data in a case of secondary Capgras delusion. Psychopathology 1994;27:211-214.

78 Sidoti V, Lorusso L: Multiple sclerosis and Capgras' syndrome. Clin Neurol Neurosurg 2007;109:786-787.

-79 Sellal F, Fontaine SF, van der Linden M, Rainville C, Labrecque R: To be or not to be at home? A neuropsychological approach to delusion for place. J Clin Exp Neuropsychol 1996;18:234-248.

80 Kim E: A post-ictal variant of Capgras' syndrome in a patient with a frontal meningioma. A case report. Psychosomatics 1991;32: 448-451.

-81 Alexander MPMD, Stuss DTPD, Benson DFMD: Capgras syndrome: A reduplicative phenomenon. Neurology 1979;29:334-339.

-82 Bouckoms AMBCB, Martuza RMD, Henderson MPD: Capgras syndrome with subarachnoid hemorrhage. J Nerv Ment Dis 1986;174:484-488.

83 Malloy PPD, Cimino CPD, Westlake RMD: Differential diagnosis of primary and secondary Capgras delusions. Neuropsychiatry Neuropsychol Behav Neurol 1992;5:83-96.

84 Holt AEM, Albert ML: Cognitive neuroscience of delusions in aging. Neuropsychiatr Dis Treat 2006;2:181-189.

85 Horikawa H, Monji A, Sasaki M, Maekawa T, Onitsuka T, Nitazaka Y, Hirano Y, Hirano S, Hashioka S, Kato T, Yoshida I, Kanba S: Different SPECT findings before and after Capgras' syndrome in interictal psychosis. Epilepsy Behav 2006;9:189-192.

86 Eren I, Civi I, Yildiz M: Frontoparietal hypoperfusion in Capgras syndrome: a case report and review. Turk Psikiyatri Derg 2005; 16:284-290.

87 Joseph AB, O'Leary DH, Wheeler HG: Bilateral atrophy of the frontal and temporal lobes in schizophrenic patients with Capgras syndrome: a case-control study using computed tomography. J Clin Psychiatry 1990; $51: 322-325$

$\checkmark 88$ Benson DF, Stuss DT: Frontal lobe influences on delusions: A clinical perspective. Schizophr Bull 1990;16:403-411.

-89 Jackson RS, Naylor MW, Shain BN, King CA: Capgras syndrome in adolescence. J Am Acad Child Adolesc Psychiatry 1992;31:977983.

90 Signer SF: Capgras symptom and delusions of reduplication in neurologic disorders. Neuropsychiatry Neuropsychol Behav Neurol 1992;5:138-143.
91 Kumar V: Capgras syndrome in a patient with dementia. Br J Psychiatry 1987;150: 251.

92 Baldwin RC, Snowden JS, Mann DMA: Delusional misidentification in association with cortical Lewy body disease: A case report and overview of possible mechanisms. Int J Geriatr Psychiatry 1995;10:893-898.

93 Lipkin B: Capgras syndrome heralding the development of dementia. Br J Psychiatry 1988;153:117-118.

94 Oyebode F, Edelstyn NMJ, Patel A, Riddoch MJ, et al: Capgras syndrome in vascular dementia: Recognition memory and visual processing. Int J Geriatr Psychiatry 1996;11:71-73.

95 Hirstein W, Ramachandran VS: Capgras syndrome: A novel probe for understanding the neural representation of the identity and familiarity of persons. Proc Biol Sci 1997;264:437-444.

-96 Edelstyn NM, Oyebode F: Capgras syndrome in the context of multiple myeloma. Int J Geriatr Psychiatry 1998;13:645-646.

97 Edelstyn NMJ, Oyebode F: A review of the phenomenology and cognitive neuropsychological origins of the Capgras syndrome. Int J Geriatr Psychiatry 1999;14: 48-59.

98 Ellis HD, Young AW: Accounting for delusional misidentifications. Br J Psychiatry 1990;157:239-248.

$\$ 99$ Ellis HD: Cognitive neuropsychology and delusional misidentification of persons. Ann Med Psychol 2004;162:50-54.

100 Bauer RM, Demery JA: Agnosia; in Heilman KM, Valenstein E (eds): Clinical Neuropsychology, ed 4. Oxford, Oxford University Press, 2003, pp 236-295.

101 Ramachandran VS: A Brief Tour of Human Consciousness. From Impostor Poodles to Purple Numbers. New York, Pi Press, 2004.

102 Brédart S, Young AW: Self-recognition in everyday life. Cognit Neuropsychiatry 2004;9:183-197.

103 Vuilleumier P, Mohr C, Valenza N, Wetzel C, Landis T: Hyperfamiliarity for unknown faces after left lateral temporo-occipital venous infarction: A double dissociation with prosopagnosia. Brain 2003; 126:889-907.

104 Christodoulou GN: The syndrome of Capgras. Br J Psychiatry 1977;130:556-564.

105 Staton RD, Brumback RA, Wilson H: Reduplicative paramnesia: A disconnection syndrome of memory. Cortex 1982;18:2335.

106 Margariti MM, Kontaxakis VP: Approaching delusional misidentification syndromes as a disorder of the sense of uniqueness. Psychopathology 2006;39:261-268.
107 Woodruff PWR, Wright IC, Bullmore ET, Brammer M, Howard RJ, Williams SCR, Shapleske J, Rossell S, David AS, McGuire PK, Murray RM: Auditory hallucinations and the temporal cortical response to speech in schizophrenia: A functional magnetic resonance imaging study. Am J Psychiatry 1997;154:1676-1682.

108 Shergill SS, Brammer MJ, Williams SCR, Murray RM, McGuire PK: Mapping auditory hallucinations in schizophrenia using functional magnetic resonance imaging. Arch Gen Psychiatry 2000;57:1033-1038.

109 Shergill SS, Bullmore ET, Brammer MJ, Williams SCR, Murray RM, McGuire PK: A functional study of auditory verbal imagery. Psychol Med 2001;31:241-253.

110 Plaze M, Martinot JL, Artiges E, Bartrès FD, Berthoz S, Paillère ML: Auditory hallucinations: Cerebral regions to be seen. Neuro Psy News 2003;2:141-150.

111 Stephane M, Barton S, Boutros NN: Auditory verbal hallucinations and dysfunction of the neuralsubstrates of speech. Schizophr Res 2001;50:61-78.

112 McGuire PK, Silbersweig DA, Frith CD: Functional neuroanatomy of verbal selfmonitoring. Brain 1996;119:907-917.

113 Gaser C, Nenadic I, Volz HP, Büchel C, Sauer H: Neuroanatomy of 'hearing voices': A frontotemporal brain structural abnormality associated with auditory hallucinations in schizophrenia. Cereb Cortex 2004;14:91-96.

114 Hunter MD, Griffiths TD, Farrow TFD, Zheng Y, Wilkinson ID, Hegde N, Woods W, Spence SA, Woodruff PWR: A neural basis for the perception of voices in external auditory space. Brain 2003; 126:161169.

115 Woodruff PWR: Auditory hallucinations: Insights and questions from neuroimaging. Cognit Neuropsychiatry 2004;9:7391.

116 Santhouse AM, Howard RJ, ffytche DH: Visual hallucinatory syndromes and the anatomy of the visual brain. Brain 2000; 123:2055-2064.

117 Rees G: Neural correlates of visual consciousness in humans. Philos Trans R Soc Lond B Biol Sci 2007;362:877-886.

118 Hoksbergen I, Pickut BA, Marien P, Slabbynck H, Kunnen J, De Deyn PP: SPECT findings in an unusual case of visual hallucinosis. J Neurol 1996;243:594-598.

119 Stoerig P: The neuroanatomy of phenomenal vision: A psychological perspective. Ann NY Acad Sci 2001;929:176-194.

120 Weiss AP, Heckers S: Neuroimaging of hallucinations: A review of the literature. Psychiatry Res 1999;92:61-74.

121 Wunderlich G, Suchan B, Volkmann J, Herzog H, Homberg V, Seitz RJ: Visual hallucinations in recovery from cortical blindness: Imaging correlates. Arch Neurol 2000;57:561-565. 